\title{
Monitoring and delinquency
}

Karen J. Weintraub and Martin Gold The University of Michigan, USA

\begin{abstract}
This study examined the effects of parental monitoring in order to discover specific ways that their relationships with their parents affect adolescents' delinquent behaviour. Data were taken from the National Survey of Youth 1972, a survey of a representative sample of 1395 Americans in the age range 11-18 years. Conditions such as the age and sex of the respondents, their affectional relationships with their parents, the composition of their families and their estimates of the delinquency of their friends all qualified the relationship between parental monitoring and their self-reported delinquency. In one condition, the generally negative relationship was reversed.
\end{abstract}

Moving beyond the well-established proposition that parenting affects adolescents' delinquent behaviour, students of delinquency have attempted to specify the critical parental practices and styles that make a difference. They have turned to an obvious possibility - the degree to which parents keep an eye on their offspring. Assuming that parents generally want their offspring to behave well and will effectively achieve that if they know what their adolescents are up to, supervision, or monitoring as it is often called, has been hypothesised to inhibit delinquent behaviour (see Rutter \& Giller, 1984; Loeber \& StouthamerLoeber, 1986; Snyder \& Patterson, 1987).

The findings have been mixed, however. Loeber and Stouthamer-Loeber (1986) reviewed 10 studies and found that in 9 of them, more parental supervision was associated with less delinquency, but not in the tenth. Riley and Shaw (1985) report that delinquent behaviour of girls, but not of boys, is negatively related to parental supervision. 
Patterson and Stouthamer-Loeber (1984), however, found that parental monitoring of sons was negatively correlated with the boys' self-reported delinquent behaviour and also with their official delinquency records.

What are the reasons for the inconsistencies in these findings? Is it the samples observed, the different definitions or operations for parental monitoring and delinquency, the failure to control for other variables, or the neglect of interacting variables that condition the relationship between monitoring and delinquency?

We note that different findings are apparently not distinguished by substantially different measures of monitoring or of delinquency. The supervision is typically indirect parents knowing the whereabouts of their offspring, who they are with, and what they are doing - rather than direct surveillance. Delinquent behaviour is typically measured with self-reports, using similar interview protocols. Differences seem to lie rather in the absence of controls for inter-related variables, for example, age and sex, which are related to both parental supervision and the adolescents' delinquent behaviour, are often confounded in the findings.

Theoretical and empirical handling of mediating variables also has contributed to apparent contradictions among studies. For example, Riley and Shaw (1985) replicated Patterson and Stouthamer-Loeber's (1984) finding that parental monitoring was negatively associated with boys' delinquent behaviour; however, they negated it with a control on boys' perceptions of their friends' delinquency. This does not necessarily mean that monitoring has no effect on the delinquency of boys; one interpretation is that monitoring affects delinquency because it prevents boys from associating with delinquent companions. That Riley and Shaw's control on the deviancy of friends does not greatly affect the relationship between monitoring and girls' delinquency suggests that perhaps delinquent companions are not as important to girls.

The study reported here addresses some of these issues by extending previous research in several ways. First, the data are taken from a representative sample of American adolescents, aged 11-18 years (Gold \& Reimer, 1975). Secondly, controls are imposed to disentangle the effects of age and sex from the effects of parental monitoring. Thirdly, potentially important mediating and interactive effects are investigated in order to determine if parental 
supervision affects delinquency differently for boys and girls, or for younger and older adolescents. Further, our investigation of interactive effects extends research on parental monitoring into an as yet unexplored region: we take parental affection into account. Both Schaefer (1959) and Becker (1964) have pointed out that parent-child relationships can usefully be considered to vary along two main axes - autonomy and affection. They propose that most of the theory and findings on the effects of parenting on children's behaviour and psychological condition can be understood in terms of the interaction of these two independent dimensions. Findings on the effects of different types of parenting (authoritarian, democratic, permissive etc.) (Elder, 1962; Baumrind, 1965), defined jointly by autonomy and affection, confirm the value of this approach. This view suggests that the effect of monitoring, one facet of autonomy, on delinquency might be conditioned by the state of the affectional relationship between parents and their children. While exploring this region, we also take into account whether an adolescent is living with both or with only one parent.

Thus we test whether parental supervision affects the level of adolescents' self-reported delinquent behaviour after controlling for age, sex, perceptions of the delinquency of friends, and for the warmth of the parent-adolescent relationship. We also test whether these variables condition the relationship between monitoring and delinquency. We aim to determine not only whether monitoring specifically affects delinquent behaviour, but also with whom and under what conditions.

\section{Method}

Sample

The data come from the second National Survey of Youth, conducted in 1972 by Gold and Reimer (1975). Respondents were selected by a multi-stage area sampling procedure: census tracts were chosen at random, with probabilities of selection proportional to population, from 40 Primary Sampling Units that had themselves been chosen at random with proportional probabilities. In the next stages blocks, then housing units, were randomly selected. If there were more than one potential respondent 
in the age range 11-18 years, only one would be selected (at random) from each household. This was done in order to obtain a more heterogeneous sample and one in which cases were independent of parents, reducing somewhat the representation of adolescents from homes with more than one offspring of 11 to 18 years old.

Interviews were obtained from 1395 of 1965 eligible adolescents, a response rate of $71 \%$. Almost all refusals came from the parents, whose written permission we required. Overall, the sample is representative of 11 to 18 year olds residing in the USA at the time, in terms of demographics such as age, sex, rural-urban residence etc.

Because the analyses required the simultaneous measurement of seven variables, a procedure for handling missing data was desirable, to avoid losing as much as $39 \%$ of the sample, primarily on account of adolescents having only one parent or surrogate caregiver or declining to estimate how delinquent their friends were. Omitting these respondents from the sample would also have limited the analysis to those from two-parent homes. Missing data for a variable (e.g. affection from father or other male caregiver) was therefore replaced with the mean score obtained from the remaining youths. Dummy variables (e.g. father or other male caregiver present/not present) were then added to the regression equations to detect whether a distinction between youths with and without missing data accounted for any variance in the dependent variable, self-reported delinquent behaviour. Twenty-eight youths declined to report their delinquent behaviour and 67 others were not monitored by the caregiver; because it was not advisable to replace these missing data, the study number reduced to 1300 .

\section{Instruments}

Each respondent was interviewed by a young adult of his or her own sex. Interviews were conducted in confidence, took on average $1 \frac{1}{2}$ hours and included a variety of response modes - open-ended and structured-response questions and card sorts.

\section{Delinquent Behaviour}

The dependent variable was measured with an index of the frequency and seriousness of the delinquent behaviours reported by the respondent. Well into the interview, the 
interviewer reminded the respondent about the confidentiality of responses and made a special request for honesty and openness. After they had sorted cards to indicate the commission of 17 kinds of delinquent acts in the previous 3 years, respondents were asked about the details of up to the three most recent offences of each kind. These included, for example, drinking and other substance abuse, truancy, theft, vandalism and assault. The score on delinquency is the sum of points, frequency weighted for seriousness, of the recent offences reported. Scores ranged from 0 (assigned to $20 \%$ of the respondents) to 22 (mean 1.83, s.d. 2.92). For further details and a discussion of the validity of self-reports, see Gold and Reimer (1975). More recent summaries of the validity of self-reports of delinquency can be found in Rutter and Giller (1984) and in Farrington (1987).

\section{Monitoring}

The primary independent variable was measured with two questions:

1. Do your parents (Does your parent) know where you are when you are away from home?;

2. Do your parents (Does your parent) know who you are with when you are away from home?

Pre-structured responses were on a 5-point scale, with 'always' as 1 and 'never' as 5. The two responses were sufficiently well correlated ( $r=0.45, P<0.001)$ to warrant summing them to compute one score for monitoring. The scale was reversed so that a high score represented more monitoring. Scores ranged from 2 to 10; mean 4.1, s.d. 1.42 .

\section{Delinquency of Friends}

Respondents were asked: 'How many (out of ten) of your friends have done ...' (the same set of 17 delinquent acts described above). Their estimates were summed. The range is $0-101$; mean 27.0 , s.d. 17.4.

\section{Parent-Adolescent Affection}

Two indices, one pertaining to fathers and one to mothers, were derived from factor analyses of a larger set of items (see Gold \& Reimer, 1975). Items measuring mother's affection were: 
1. 'My mother gives me the right amount of affection.'

2. 'My mother and I do things together that we both enjoy doing:'

3. 'I agree with my mother's ideas and opinions about things.'

4. 'I want to be like my mother.'

5. 'My mother makes it easy for me to confide in her.'

6. 'I feel close to my mother.';

7. 'As I was growing up, my mother tried to help me when I was scared or upset.'

The first six items also appeared in the index for fathers, with appropriate changes in reference; the seventh item was: 'My father accepts and understands me as a person.' Respondents sorted items/cards into pre-structured categories consisting of 7-point scales, ranging from 'strongly agree' to 'strongly disagree'. Scores were computed as a mean of the summed items, a high score indicating a warmer relationship. Fathers' scores were in the range 7-35; mean 24.5, s.d. 6.10. (The index has an item-total reliability, by Cronbach's alpha, of 0.86 ). Scores for mothers were in the range 7-35; mean 25.9, s.d. 5.44, alpha 0.80 .

Sex, age and the presence of caregivers were also reported.

\section{Data Analysis}

Data analysis consisted of Pearson product-moment correlations (Pearson, 1896) and multiple regressions on standardised variables. They were performed employing the MIDAS statistical package on The University of Michigan IBM 3090-600E mainframe computer. Interaction terms for monitoring $\times$ sex and monitoring $\times$ parental affection were built by dichotomising the latter component, setting the values to 0 and 1 , then multiplying by monitoring. The interaction term for age was built differently: inspection of the correlations of monitoring with delinquency at several age levels revealed that monitoring was more closely associated with delinquency in the age range 13-16 years, so the age value for those aged 11-12 and 17-18 was set to 0 and the values for the 13-16 year olds to 1 before multiplying by the monitoring score. In this way, the variable of age was adapted so that the hypothesis that the conditioning effect of age is curvilinear could be tested under the linear assumption of multiple regression. 


\section{Results}

The zero-order correlations among the variables are shown in Table 1. Consistent with previous studies, monitoring is significantly and negatively correlated with delinquency. Also consistent with published findings, the warmer their relationships with their parents and the less delinquent their friends, the less delinquent the adolescents appeared. Critical to the design of this data analysis are the significant zero-order correlations between age and sex on the one hand and monitoring and delinquency on the other. Clearly, a precise assessment of the relationship between monitoring and delinquent behaviour requires that age and sex be controlled, otherwise the relationship of age or sex to delinquency might erroneously be attributed to parental monitoring. Indeed, as the last row in

Table 1 Correlations $\left(x_{S}\right)$ and selected partial correlations $(n=1300)$.

\begin{tabular}{lrrrrrrr}
\hline & \multicolumn{7}{c}{ Variable } \\
\cline { 2 - 8 } & 1 & 2 & 3 & 4 & 5 & 6 & 7 \\
\hline Age & 1.00 & & & & & & \\
Sex & -0.03 & 1.00 & & & & & \\
Monitoring & -0.20 & 0.25 & 1.00 & & & & \\
Father's affection & -0.25 & -0.13 & 0.26 & 1.00 & & & \\
Mother's affection & -0.23 & 0.13 & 0.37 & 0.43 & 1.00 & & \\
Friends' delinquency & 0.20 & -0.05 & -0.28 & -0.19 & -0.18 & 1.00 & \\
Delinquency & 0.19 & -0.28 & -0.26 & -0.11 & -0.18 & 0.34 & 1.00 \\
Delinquency & & & -0.18 & -0.11 & -0.11 & 0.31 & \\
(partialled on age and sex) & & & & & & & \\
\hline
\end{tabular}

Table 1 indicates, when the effects of age and sex are partialled out, the correlation between delinquency and monitoring declines substantially. (There is no statistical test to assess whether the difference between a zero-order and a partial correlation is significant. Note however, that the reduction is more than three times the standard error of the zero-order correlation.)

In light of the inter-relatedness of the variables, regressions were run to determine the degree to which age, sex, the presence of parents and parental relationships, friends' delinquency and monitoring independently and jointly related to delinquent behaviour. Terms representing the 
main effects of variables and certain interactions were therefore included in successive regression equations. The findings are presented in Table 2. Standardised predictors were entered in the order indicated in Table 2. Age and sex (the control variables) were entered first, at step 0 , and accounted for $10.9 \%$ of the variance $\left(r^{2}\right)$ in delinquent behaviour. The signs on the beta weights indicate that older adolescents confessed to more delinquent acts than younger ones did, and boys more than girls.

Monitoring was entered at step 1 and accounted for a statistically significant $2.8 \%$ additional variance - the more monitoring, the less delinquent behaviour. Note that the

Table 2 Ordered stepwise regression on delinquency $(n=1300)$.

\begin{tabular}{|c|c|c|c|c|c|c|}
\hline & \multicolumn{6}{|c|}{ Step } \\
\hline & 0 & $I$ & 2 & 3 & 4 & 5 \\
\hline Age & $0.18^{\mathrm{a}}$ & $0.15^{\mathrm{a}}$ & $0.14^{\mathrm{a}}$ & $0.12^{\mathrm{a}}$ & $0.12^{\mathrm{a}}$ & $0.08^{b}$ \\
\hline Sex & $-0.27^{a}$ & $-0.23^{a}$ & -0.02 & -0.02 & -0.02 & -0.02 \\
\hline Monitoring & & $-0.18^{a}$ & $-0.20^{\mathrm{a}}$ & -0.10 & 0.11 & 0.15 \\
\hline Monitoring $\times$ age $^{d}$ & & & $-0.13^{a}$ & $-0.13^{a}$ & $-0.13^{a}$ & $-0.12^{\mathrm{a}}$ \\
\hline Monitoring $\times$ sex & & & $-0.21^{\mathrm{b}}$ & $-0.22^{\mathrm{b}}$ & $-0.22^{b}$ & $-0.17^{c}$ \\
\hline Father's affection & & & & $-0.06^{c}$ & -0.05 & -0.02 \\
\hline Monitoring $\times$ father's affection & & & & -0.15 & -0.14 & -0.16 \\
\hline Father present & & & & $-0.14^{c}$ & -0.13 & -0.11 \\
\hline Mother's affection & & & & & -0.04 & -0.04 \\
\hline Monitoring $\times$ mother's affection & & & & & -0.24 & -0.19 \\
\hline Mother present & & & & & -0.07 & -0.06 \\
\hline Friends' delinquency & & & & & & $0.32^{\mathrm{a}}$ \\
\hline Friends' delinquency $\times$ sex & & & & & & $-0.13^{a}$ \\
\hline$r^{2}$ & $0.109^{a}$ & $0.137^{\mathrm{a}}$ & $0.157^{a}$ & $0.163^{\mathrm{a}}$ & $0.166^{\mathrm{a}}$ & $0.231^{\mathrm{a}}$ \\
\hline
\end{tabular}

${ }^{\mathrm{a}} P<0.001 ;{ }^{b} P<0.01 ;{ }^{c} P<0.05 ;{ }^{\mathrm{d}} 11-12$ and $17-18$ year olds compared with $13-16$ year olds.

addition of monitoring at step 1 reduces the beta weights for age and sex by very little, suggesting that less close monitoring is not a reason for boys and older respondents being more delinquent.

Terms for the interaction of age and sex with monitoring were added at step 2. The finding for the interaction of monitoring by age was anticipated by the correlations described earlier: monitoring is more closely associated with less delinquent behaviour among 13-16 year olds than among younger or older adolescents (Figure 1). The 


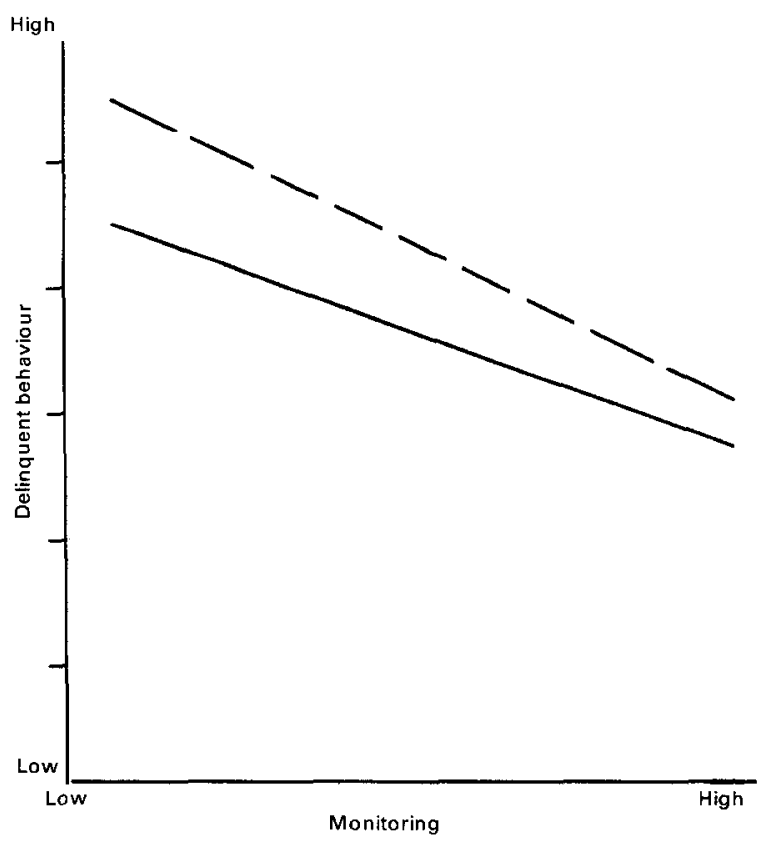

Figure 1 Relationship of monitoring to delinquent behaviour at different ages. - 11-12 and 17-18 years; - - -, 13-16 years.

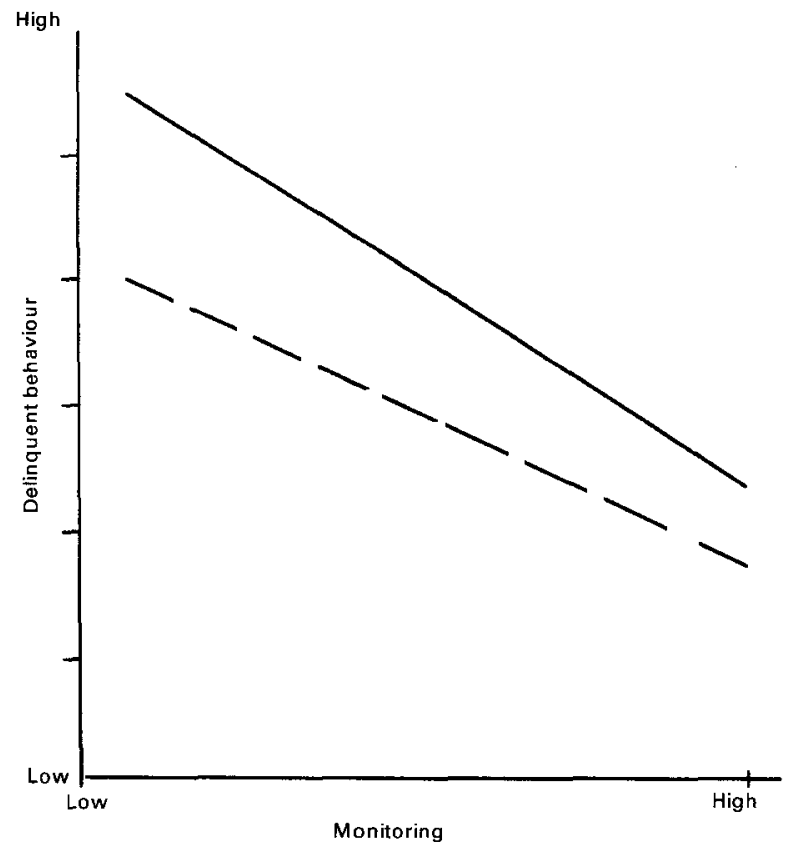

Figure 2 Relationship of monitoring to delinquent behaviour for boys (-) and girls (- - -). 
interaction involving the sex of the respondent is such that monitoring is more closely related to boys' delinquency than to that of girls. Note that the addition of the interaction term, monitoring $\times$ sex, at step 2 reduces the beta for the main effect of sex to a statistically insignificant -0.02 . As shown in Figure 2, the effect of sex was entirely attributable to youths who were monitored less closely, among whom the boys were more delinquent than the girls.

Parental affection was considered next, paternal at step 3 and maternal at step 4. Paternal affection accounts for a small but significant $0.6 \%$ more variance; the effect of the relationship of adolescents with their mothers is negligible. That the affection of fathers seems more important than that of mothers is not due to the order in which they were entered into the analysis; when the relationship with the mother was entered first, it was still reduced to insignificance by the addition of the fathers' affection. Thus, the greater the affection of the father, the less delinquent the adolescent.

Note also that the sign of the beta weight for monitoring changes at step 4, with the introduction of variables relating to maternal relationships. Stepwise analysis revealed that this change is due to taking into account the presence of a mother or mother-surrogate in the adolescents' home. Whilst the beta weights for monitoring in step 3 or step 4 are not statistically significant, the difference in their signs suggests that monitoring itself related differently to delinquent behaviour in the absence of a mother, tending to become positively correlated. Indeed, the correlation of monitoring with delinquency in the presence of a mother is -0.18 and in the absence is +0.18 (age and sex controlled for). The difference between these correlations is significant $(P=0.05)$. A closer look revealed that the effect is more pronounced among girls (age-controlled, -0.18 and +0.42 , respectively) than among boys $(-0.19$ and +0.11 , respectively).

Note that taking into account the paternal relationship at step 3 reduces the beta weight of monitoring by half. This indicates that the apparently negative relationship of monitoring to delinquency may be spurious, due at least partly to the positive association of monitoring with perceived paternal affection. Another possible interpretation is that paternal affection mediated the relationship between monitoring and delinquency, i.e. monitoring enhanced the relationship which in turn inhibited delin- 


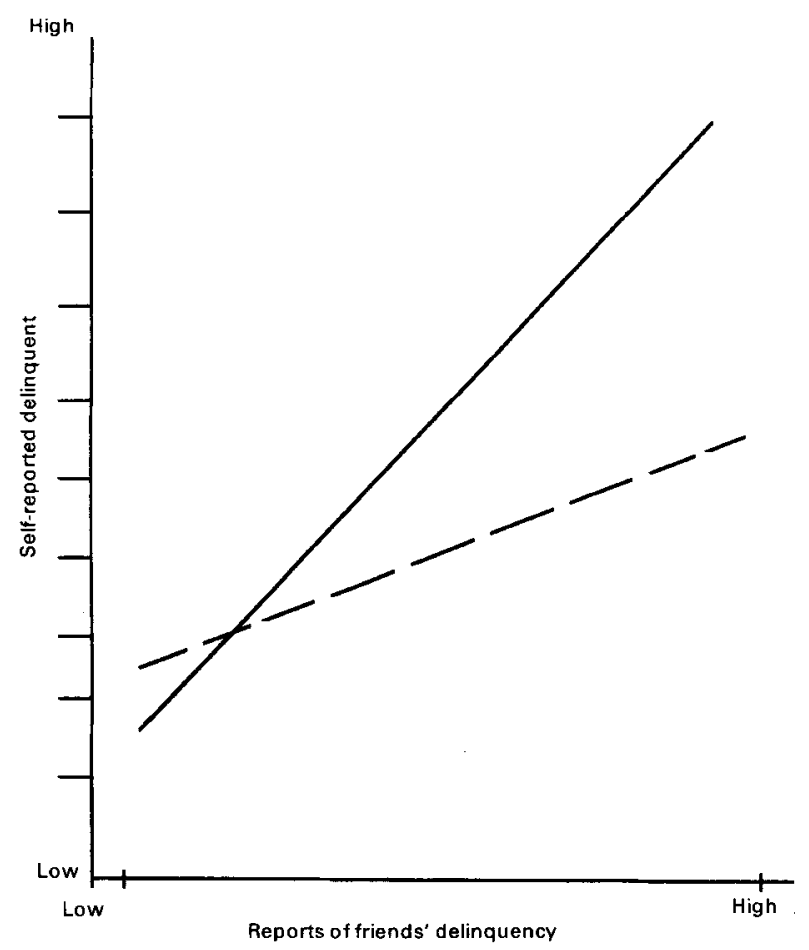

Figure 3 Relationship of reports of friends' delinquent behaviour to delinquent behaviour for boys (-) and girls (- - -).

quency. (Findings of the superior socialising effects of authoritative over 'laissez-faire' styles of parenting (Elder, 1962; Baumrind, 1965) support the latter interpretation.)

Finally, at step 5, respondents' assessments of the delinquency of their friends were brought into the analysis, and accounted for an additional $6.5 \%$ of the variance. The significant main effect means that the more adolescents described their friends as delinquent, the more delinquency they admitted themselves. The significant interaction of friends' delinquency and sex is depicted in Figure 3: delinquency of boys was more closely associated with the perceived delinquency of their friends than that of girls.

\section{Discussion}

Our data show that the relationship between parental monitoring and delinquent behaviour in this representative sample of American adolescents in 1972 was partly due to the relationships of both of these variables to other 
variables: the relationship is diminished substantially when age and sex are controlled, but it remains statistically significant; less supervision was associated with more delinquency, this was most true among boys, especially 13to 16-year-old boys.

The relationship between monitoring and delinquency was further qualified by other conditions and was actually reversed under one. Other things being equal, monitoring by a single father was associated with elevated selfreported delinquency, especially that of girls.

The affectional relationships adolescents reported having with their parents, especially with their fathers, seem to have qualified some of the relationship of monitoring to delinquency: delinquency tended to be lower where monitoring and affection were higher.

When respondents' reports of the delinquency of their friends were entered into the regression equation, we replicated the finding of Riley and Shaw (1985): the effect of monitoring on boys - but not on girls - declined to statistical insignificance (data not shown here). It may be plausibly inferred that monitoring affects boys' delinquency by preventing them from associating with an appreciative audience for their delinquent performance, which may be a critical factor (Cohen, 1955; Gold, 1979). As we have seen, taking into account relationships of adolescents with their parents also markedly diminishes the predictive power of monitoring.

In short, the relationship of parental monitoring to their children's delinquency was negative under most conditions. This relationship was qualified, however, by the conditions of age, sex, parental relationships and the delinquency of the adolescents' friends, conditions which were themselves inter-related. Even in a sample as large as ours, data analysis reached a point where the number of effective relationships overwhelmed their complicated inter-relations with delinquency, suggesting that monitoring should be counted as a source of control over delinquency only in context. This study has made some advances, we believe, in specifying what those contexts are.

Having stated this, at least two caveats are in order. One is to recognise the caution with which correlation should be interpreted as causation. While it seems to be commonsense, for example, that parental supervision inhibits delinquent behaviour, the reverse is also plausible - that 
adolescents' intentions to be delinquent determine the degree to which their parents can effectively monitor their behaviour. The second is that our data are based entirely on one set of respondents; we do not have independent verification from parents of the level of monitoring they exert or independent measures of the delinquency of our respondents or of their friends. From one perspective this is no problem; we are concerned with adolescent behaviour, and so it is appropriate to assess potential determinants from the adolescent point of view. Still, independent measures would give us a better view of the social reality.

Further research may resolve some of the remaining ambiguities; for example, parental training that effectively increases monitoring of at-risk adolescents (such as male school failures) and strengthens their affectional ties to parents can be a treatment component in a before-after treatment-control group design. Causal sequences and the mediation of factors such as association with deviant peers could in this way be determined with more certainty. Multiple sources of information, e.g. parents and friends, could usefully be tapped in the course of such experiments.

\section{References}

Baumrind, D. (1965). Parental control and parental love. Children 12, 230-234.

Becker, W.C. (1964). Consequences of different kinds of parental discipline. In: M.L. Hoffman \& L.W. Hoffman, eds, Review of Child Development Research. Vol. I, pp. 169-208. New York: Russell Sage Foundation.

Cohen, A.K. (1955). Delinquent Boys. Chicago: The Free Press.

Elder, G.H. Jr (1962). Structural variations in the child rearing relationship. Sociometry 25, 241-262.

Farnington, D.P. (1987). Epidemiology. In: H.C. Quay, ed, Handbook of Juvenile Delinquency, pp. 33-61. New York: Wiley.

Gold, M. (1979). Scholastic experiences, self esteem, and delinquent behavior: a theory for alternative schools. Crime and Delinquency 24, 290-308.

Gold, M. \& Reimer, D.J. (1975). Changing patterns of delinquent behavior among Americans 13 through 16 years old: 1967-1972. Crime and Delinquency Literature 1, 483-517.

Loeber, R. \& Stouthamer-Loeber, M. (1986). Family factors as correlates and predictors of juvenile conduct problems and delinquency. In: M. Tonry \& N. Morris, eds, Crime and Justice, Vol. 7, pp. 29-149. Chicago: University of Chicago Press.

Patterson, G.R. \& Stouthamer-Loeber, M. (1984). The correlation of family management practices and delinquency. Child Development 55, $1299-1307$.

Pearson, K. (1896). Mathematical contributions to the theory of evolution. III. Regression, heredity and panmixia. Philosophical Transactions of the Royal Society of London, Series A 187, 253-318. 
Riley, D. \& Shaw, M. (1985). Parental supervision and juvenile delinquency. Home Office Research Study No. 83. London: HMSO.

Rutter, M. \& Giller, H. (1984). Juvenile Delinquency. New York: The Guilford Press.

Schaefer, E.S. (1959). A circumplex model for matemal behavior. Journal of Abnormal and Social Psychology 59, 226-235.

Snyder, J. \& Patterson, G.R. (1987). Family interaction and delinquent behavior. In: H.C. Quay, ed, Handbook of Juvenile Delinquency, pp. 216-243. New York: Wiley.

Address correspondence to Martin Gold, Institute for Social Research, Box 1248, Ann Arbor, Michigan, MI 48106, USA. 